\title{
INITIAL OXIDATION KINETICS OF COPPER FILMS INVESTIGATED BY IN-SITU UHV- TEM
}

GUANG-WEN ZHOU, JUDITH C.YANG

Department of Materials Science and Engineering, University of Pittsburgh,Pittsburgh, PA 15261.

In the study of metal oxidation, there is a wide gap between information provided by surface science methods and that provided by bulk oxidation studies. The former have mostly examined the adsorption of up to $\sim 1$ monolayer (ML) of oxygen on the metal surface, while as both low and high temperature bulk oxidation studies have mainly focused on the growth of an oxide layer at the later stages of oxidation. Hence, we are visualizing the initial oxidation stages of a model metal system by in situ ultra-high vacuum (UHV) transmission electron microscopy (TEM), where the surfaces are atomically clean, in order to gain new understanding of these ambiguous stages of oxidation. We have previously studied that the growth of $\mathrm{Cu}_{2} \mathrm{O}$ islands during initial oxidation of $\mathrm{Cu}(100)$ film. ${ }^{1,2} \mathrm{We}$ are presently investigating the initial stages of $\mathrm{Cu}(110)$, and $\mathrm{Cu}(111)$ oxidation, from $10^{-4}$ Torr $\mathrm{O}_{2}$ to atmospheric pressures and temperature range from room temperature to $700^{\circ} \mathrm{C}$.

Single crystal $99.999 \%$ pure $1000 \AA \mathrm{Cu}$ films were grown on (110) and (111)NaCl in an UHV e-beam evaporator system, where the base pressure was $10^{-10}$ torr. The $\mathrm{Cu}$ film was mounted on a specially prepared Si mount which along with the modified specimen holder, allows for the resistive heating of the specimen. The microscope was a modified JEOL200 CX with a spatial resolution of $2.5 \AA$ and permits introduction of gasses via a leak valve. ${ }^{5}$ To remove the native oxide formed due to oxidation in air, the specimen was annealed at $350{ }^{\circ} \mathrm{C}$ and to remove the $\mathrm{Cu}_{2} \mathrm{O}$ formed due to in situ oxidation, annealing was followed by exposure to methanol. ${ }^{6}$

Figures a-c are the bright field images when the $\mathrm{Cu}$ films were oxidized at $350^{\circ} \mathrm{C}$ but different with orientations. The oxidation rate of $\mathrm{Cu}(111)$ is $\sim 20$ times faster than the other two orientations. At a higher temperature of $500^{\circ} \mathrm{C}$ as shown in Figures (d), (e), (f), the morphologies of $\mathrm{Cu} 2 \mathrm{O}$ islands formed on different orientations of $\mathrm{Cu}$ films are dramatically different from each other. The $\mathrm{Cu} 2 \mathrm{O}$ islands on $\mathrm{Cu}(100)$ are square-based pyramids, with no sharp contrast within islands. The islands on $\mathrm{Cu}(110)$ are trapezoid in cross-section. Oxidation of $\mathrm{Cu}(111)$ revealed a continuous growth of oxide with cellular morphology, while the overall oxide layer shows 3-fold symmetry when it grows to very larger $(>1 \mu \mathrm{m})$, and side facets are formed.

This research is funded by the National Science Foundation (DMR \# 9902863), NACE seed grant, and Department of Energy (DEFG02-96ER45439). The experiments were performed at the Materials Research Laboratory, UIUC. The authors thank Ray Twesten, Kevin Colrary for their help.

\section{Reference}

1. J.C. Yang, M. Yeadon, B. Kolasa and J.M. Gibson, Appl. Phys. Lett., 70, 26 (1997)

2. J.C. Yang, M. Yeadon, B. Kolasa and J.M. Gibson, Scripta Materalia, 38, 8 (1998)

3. J.C. Yang, B. Kolasa and J.M. Gibson, Appl. Phys. Lett., 73, 19 (1998).

4. M.L. McDonald, J.M. Gibson and F.C. Underwald, Rev. Sci. Instrum. 60, 700 (1989)

5. J.C. Yang, M. Yeadon, D. Olynick and J.M. Gibson, Microsc. Microanal. 3, 121 (1997)

6. N. Cabrera and N.F. Mott, Rep. Prog. Phys. 12, 163 (1948). 


\section{$\mathrm{T}=350^{\circ} \mathrm{C}$}
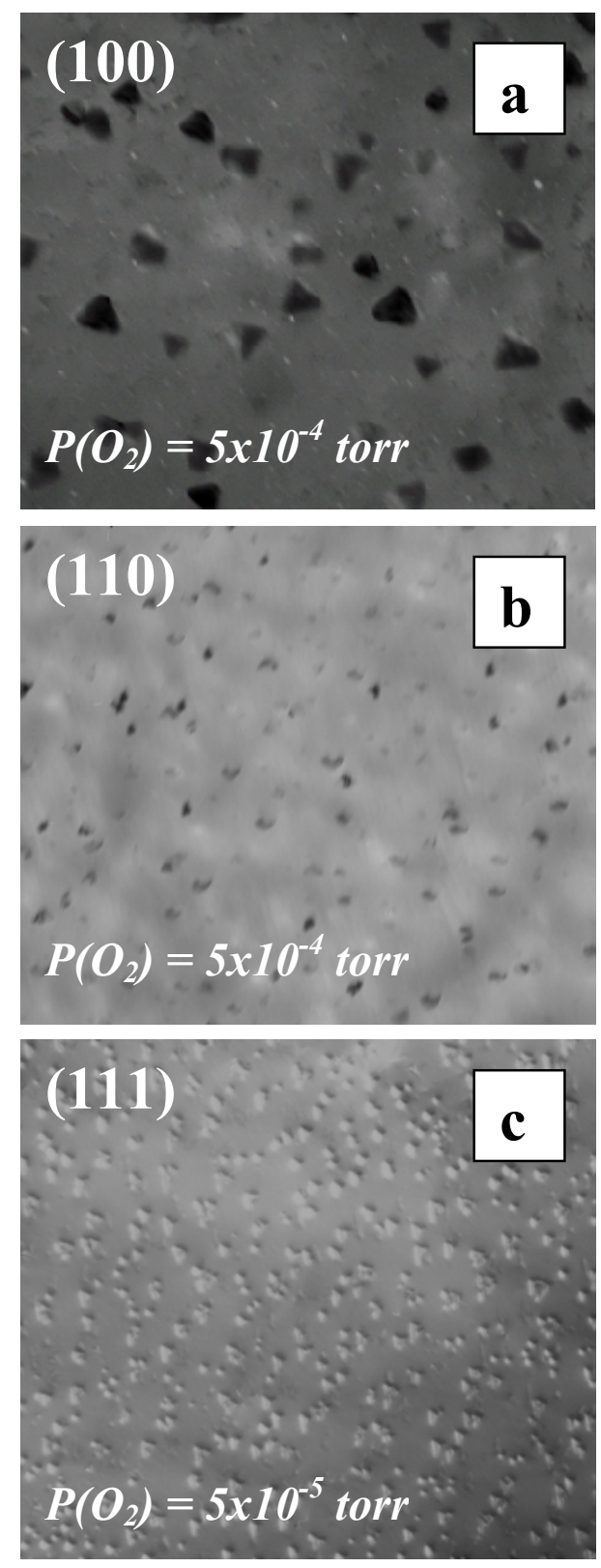

\section{$\mathrm{T}=5^{500} \mathrm{C}$}
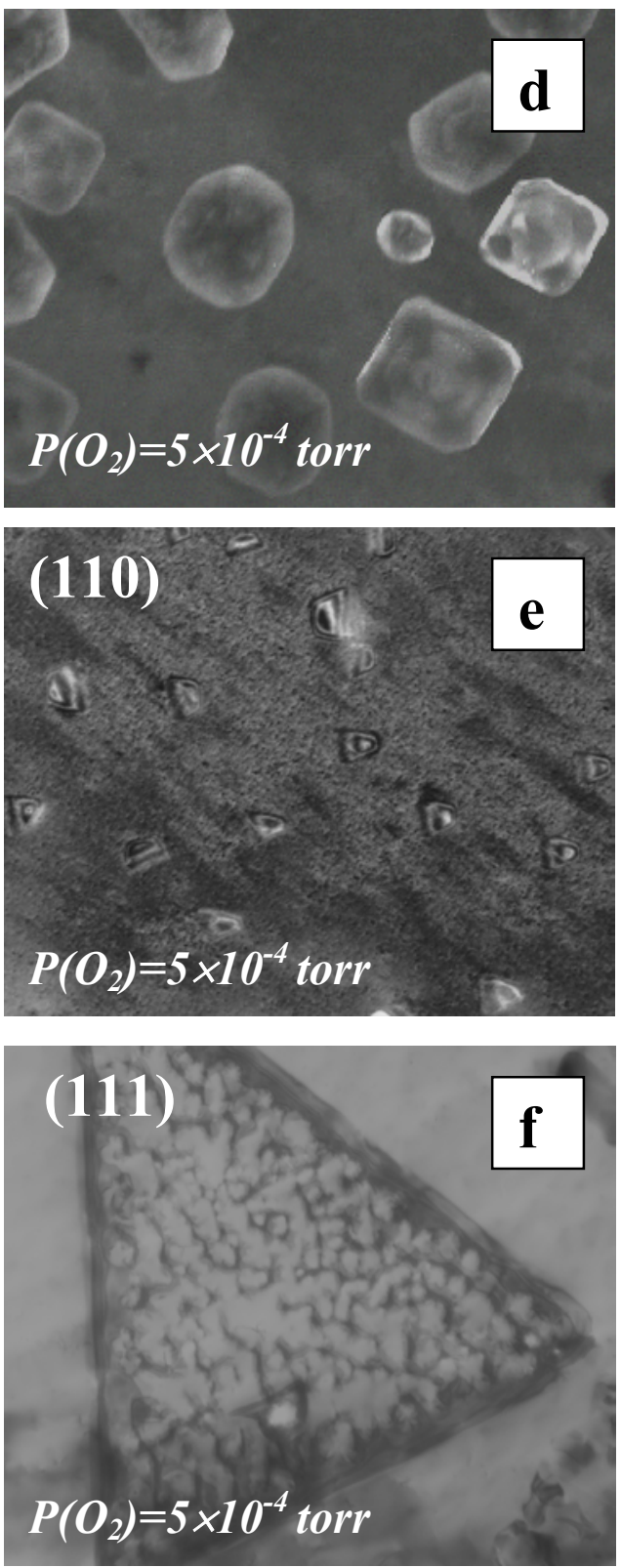

Figure: Oxidation of $\mathrm{Cu}$ films at $350^{\circ} \mathrm{C}$ for (a) $\mathrm{Cu}(100)$ at $\mathrm{P}\left(\mathrm{O}_{2}\right)=5 \times 10^{-4} \mathrm{Torr}$ for $20 \mathrm{~min}$; (b) $\mathrm{Cu}(110)$ at $\mathrm{P}\left(\mathrm{O}_{2}\right)=5 \times 10^{-4}$ Torr for $10 \mathrm{~min}$; (c) $\mathrm{Cu}(111)$ at $\mathrm{P}\left(\mathrm{O}_{2}\right)=5 \times 10^{-5}$ Torr for $5 \mathrm{~min}$; and $500^{\circ} \mathrm{C}$ for $(\mathrm{d}) \mathrm{Cu}(100)$ at $\mathrm{P}\left(\mathrm{O}_{2}\right)=5 \times 10^{-4}$ Torr for $20 \mathrm{~min}$; (e) $\mathrm{Cu}(110)$ at $\mathrm{P}\left(\mathrm{O}_{2}\right)=5 \times 10^{-4}$ Torr for $10 \mathrm{~min}$; and (f) $\mathrm{Cu}(111)$ at $\mathrm{P}\left(\mathrm{O}_{2}\right)=5 \times 10^{-5}$ Torr for $10 \mathrm{~min}$. 